\title{
Interactive comment on "Changing patterns of extreme water levels in urbanizing plain river network region of Taihu Basin, China: characteristics and causes" by Y. Wang et al.
}

\author{
Y. Wang et al. \\ xypnju@163.com \\ Received and published: 4 August 2016
}

The manuscript studied the temporal trend and change point of the annual maximum and minimum water level in Taihu Basin, China. The studies used an interesting high quality data sets which is the daily water level datasets from 1960 to 2012 at 8 stations in the basin. Despite this interesting data set, the case study considered in the manuscript is very basic, and scientific contribution looks limited. The paper also suffers from serious flaws on the methodology and some conclusions are not supported by evidence. In my opinion, the current manuscript does not meet the standard of HESS, which still requires substantial improvement.

Discussion paper

Author answer: We really appreciate this reviewer's very valuable and constructive 
advice on our manuscript. It will greatly help us to improve the quality of our manuscript. As the reviewer said, we conducted a basic research in this manuscript. However, as far as our knowledge, such study on long-term changes in extreme water level in this region is very limited. In recent decades, due to the rapid urbanization, the hydrological regimes have been changed heavily in this region. Therefore, we take comprehensive researches on the changes in water level at first. Certainly, as the reviewers expected, some further work on rainstorm modeling and flood risk will go on in our further work.

As these general comments are reïňćected in the following speciïñ Ąc comments, we will address them as follows:

Comment 1: - Page 3, line 30. The thiessen polygons method (Jones and Hulme, 1996) was used to calculate regional extreme water level series. However, these kinds of method are usually not theoretically justified for extreme data sets (e.g. annual maximum or annual minimum), because extreme data are usually highly skewed. Thus an acceptable way to regionalizing the extreme data set is to firstly regionalizing the daily water level time series at different locations, then calculate the maximum or minimum. The reverse of this procedure is not correct.

Author answer: Thanks for this comment. As the Reviewer suggested, it is not appropriate that we select the thiessen polygons method to calculate the regional extreme water level. According to the comment, we will reanalyze the characteristic of extreme water level through at-site data in our revised manuscript.

Comment 2: However, owning such a high-quality data set, I suggest to consider some regional models to study at-site extreme data, rather than regionalizing to one time series, in which huge amount of information can be lost during the process of regionalization. Focusing directly the at-site data could provide a better understand on how the extreme water level changes at each site due to climate and human activities. I think it could be interesting to consider some extreme values distribution to quantify such risks. However, just reporting the existence of trend is not enough. Authors could con-

Printer-friendly version

Discussion paper 
sider some of the following references for the regional approaches on extreme events. Leclerc, M. and T. B. M. J. Ouarda (2007). "Non-stationary regional flood frequency analysis at ungauged sites." Journal of Hydrology 343(3-4): 254-265. Maraun, D., et al. (2011). "The influence of synoptic airflow on UK daily precipitation extremes. Part I: Observed spatio-temporal relationships." Climate Dynamics 36(1-2): 261-275. Sun, $X$., et al. (2014). "A general regional frequency analysis framework for quantifying local-scale climate effects: A case study of ENSO effects on Southeast Queensland rainfall." Journal of Hydrology 512(0): 53-68. Chen, X., et al. (2014). "Climate information based streamflow and rainfall forecasts for Huai River basin using hierarchical Bayesian modeling." Steinschneider, S. and U. Lall (2015). "A hierarchical Bayesian regional model for on stationary precipitation extremes in Northern California conditioned on tropical moisture exports." Water Resources Research 51(3): 1472-1492.

Author answer: According to the Reviewer's suggestion, we will reanalyze the characteristic of water level through at-site data. What's more, we also have read the recommended references carefully. We also think it's very interesting and meaningful to quantify flood risk in this region combining regional model and extreme values theory. Such study can help us better understand the characteristic of extreme events. I think this valuable advice points out the direction for our further study.

Comment 3: - A follow up question is that in page 9 line 12 authors mentioned heterogeneity of rainfall in Taihu Basin (Deng et al., 2014åřśäžĘè£ŹçcrĞæǘ̆ĞçŇő). It is not clear why regionalizing the extreme water level data in this heterogeneous region is appropriate, because regionalizing data usually requires to be in the homogeneous region.

Author answer: Thanks for this comment. We mentioned the heterogeneity of rainfall in this reference refers to uneven distribution at the time scale. As we all know, the Taihu Basin is controlled by the East Asia Monsoon and the precipitation is mainly concentrated in the wet season (May to September). According to Deng et al., (2014), the concentration of precipitation in wet season has an uptrend, which may contribute

Printer-friendly version

Discussion paper
Interactive

comment 
to water level increasing. What's more, we will reanalyze the characteristic of extreme water level through at-site time series in our revised manuscript.

Comment 4: - Page 8, line 17, the precipitation is not well defined (Monthly? Daily?) Beta and $z$ are not defined in Table 3 . Authors attempt to use rainfall as a main predictor to estimate the contribution of climate on the maximum and minimum water level. However, selecting the rainfall at different periods (e.g. summer rainfall, annual rainfall) or different events (e.g. average rainfall, $n$-days cumulative rainfall and daily maximum rainfall) could lead to a very different result. Thus it is not rigorous to select the predictors arbitrarily.

Author answer: Thanks for this valuable advice. Actually, we selected the annual precipitation as predictor to estimate the maximum and minimum water level in our original manuscript. According to the the statistical results, we found that the maximum and minimum water level occurred during the wet and dry season, respectively. Considering the Reviewer's suggestion, we will use the climate factors of wet season to estimate the maximum water level and use the climate factors of dry season to estimate the minimum water level. Besides precipitation, the evaporation also will be considered as a climate factor to estimate water level. Details can be referred to Comment 6 . In addition, we will clarify these definitions (Beta and Z) in our revised manuscript according to the Reviewer's suggestion,

Comment 5: - Page 8, line 21-30. I disagree that the authors account for all those variation that could not be explained by rainfall as human activities. To account for the impact of human activities, authors need to conduct a quantitative investigation on each human activity, such as land use, and assess their impacts. Besides the climate and human activities, there is also a portion of variation (an error term or residual) which could not be captured by either of these aspects. Thus the methods of quantifying the impact of human activities is problematic.

Author answer: Thanks for this comment. In this study, we use this method to investi- 
gate whether climate change or anthropogenic factor should be responsible for hydrological variation at different periods across the basin. Actually, the Reviewer's advice is very constructive for understanding the hydrological variation caused by human activity. As we all know, this region has experienced many kinds of human activities due to urbanization during the recent decades, such as land use changes, river network reduction, and hydraulic engineering constructions. It is very interesting and meaningful to investigate hydrological variation from each human activity on in this region. Because it's very difficult to investigation their separate impacts on water level alteration across the entire region due to the limited of human activity data. But I think it's feasible to carry out such research in a small basin through hydrologic model and the Reviewer's advice points out the direction for our further study. However, urbanization area is not homogeneously distributed in this region. We will try to explore what relationship it is between urbanization distribution and the alteration of water level in our revised manuscript.

Comment 6: Furthermore, just using rainfall to account for climate factors is also problematic. A linear regression based on rainfall (it is not clear which kinds of rainfall is used here) was used to estimate the annual minimum and maximum water level. However, Fig 7 showed that the correlation between the rainfall and water level is quite weak after 1989. Thus "rainfall" used here is certainly not a good predictor. As a consequence, just using rainfall to calculate H_HP is not appropriate. Calculating $\mathrm{H} \_\mathrm{hp}$ should accounts for all climate factors besides rainfall, such as evaporation.

Author answer: Thanks for this valuable suggestion. According to the Reviewer's advice, it is not appropriate that we just used annual precipitation to estimate extreme water level. So we will select the precipitation and evaporation to rebuild the relationship between extreme water level and climate factors during the baseline period in the revised manuscript. Then, we will reanalyze water level variability attribution through the relationship equation. In original manuscript (Fig 7), the correlation coefficient between extreme water level and annual precipitation is high during the baseline period

Printer-friendly version

Discussion paper 
(1960-1988), so we only used the equation in the baseline period to calculate HHP in activity period. Considering the Reviewer's suggestion, the whole time series will be divided according to decade scale (i.e. 1960-1969, 1970-1979, 1980-1989, 1990-1999, 2000-2012). Meanwhile, Fig 7 will be modified and some relevant paragraphs also will be rewritten in our revised manuscript.

Interactive

Additional comments:

Comment 7: - Page 2, Line 23, what is $\mathrm{km} / \mathrm{km} 2$ ?

Author answer: It is the unit of river density. River density is the total length $(\mathrm{km})$ of river networks in unit basin area (km2), which was firstly introduced by Horton (1945). We will rewrite this sentence and add related notes in our revised manuscript.

Comment 8: - Page 6, lines 20. Curve of statistics UF (and also UB) have never been defined, whereas UF is sometimes used as the normalized variables (removing the mean and divide by the standard deviation). UB is similar to UF, but calculated using the reversed data. This definition needs to be clearly stated in the manuscript.

Author answer: We agree. We will add the definition of statistics UF and UB in our revised paragraph according to the Reviewer's advice. Comment 9: - Page 6, line 29, why obvious?

Author answer: According to the Yue et al., (2002), the existence of serial correlation may increases the probability that the Mann-Kendall test will detect a significant trend. In this study, the lag-1 R of extreme high water level (EHWL) is lower than that of extreme low water level (ELWL). It is because that EHWL is a strong random sample, the occurrences of which are usually accompanied by heavy precipitation. The ELWL occurs in the dry season and its value range is smaller than that of EHWL, which lead to high serial correlation. We will revise this sentence in our revised paragraph to enhance readability.

Comment 10: - Page 7, line 5. How to support this judgement? References are re-

Printer-friendly version

Discussion paper 
quired.

Author answer: We will add relevant references in this sentence when we revise it.

Interactive comment on Hydrol. Earth Syst. Sci. Discuss., doi:10.5194/hess-2016-184, 2016.

Interactive

comment

Printer-friendly version

Discussion paper 